\title{
Coffee Dietary Supplement
}

National Cancer Institute

\section{Source}

National Cancer Institute. Coffee Dietary Supplement. NCI Thesaurus. Code C113662.

A dietary supplement containing coffee, with potential gastrointestinal (Gl) tract

stimulating activity. Following consumption of the dietary supplement, the coffee may

both stimulate peristalsis and may increase bowel movement. The supplement also may

also stimulate the central nervous system, suppress appetite and cause weight loss. 